\title{
Diversity and altitudinal niche width characteristics for 35 taxa of the Papua New Guinea Frullania flora with consideration of sibling pairs
}

\author{
Janice M. Glime, Peter S. Hudy, \\ Department of Biological Sciences, Michigan Technological University, Houghton, MI \\ 49931 \\ and Sinske Hattori \\ Hattori Botanical Laboratory, 3888 Obi-Honmachi, Nichinan-shi, Miyazaki-ken 889-26, \\ Japan
}

\begin{abstract}
The Frullania taxa on Mount Albert Edward, Papua New Guinea, form many associations that suggest a high degree of niche similarity, but at different altitudes, different associations form. The species diversity of the genus is greatest at the middle altitudes and least in the dry lowlands. This altitudinal separation is apparent in the niche widths of the taxa. The members of the four sibling taxa pairs examined exhibit distinct altitudinal niches, suggesting that the sibling taxa are distinct, with different niche optima.
\end{abstract}

\section{Introduction}

Niche theory suggests that when a large number of closely related taxa occur in a small geographic area we should expect to find accompanying niche separations. Inoue's collections of Frullania on Mount Albert Edward, Papua New Guinea, revealed 57 Frullania taxa, including ten infraspecific taxa pairs (Hattori 1988). These data provide an opportunity to test niche separation in this very common tropical genus.

Hattori and Piippo (1986) have shown that altitudinal distribution differs among taxa of Frullania, and Li et al. (1989) have suggested that altitude might be important in separating Frullania taxa on ordination axes. Thus, we have indications that for Frullania, altitude is an important niche parameter that can be used as an ecological descriptor.

Diversity is related to niche width, and as fewer niches become available, the diversity diminishes. As the tropical conditions that favor Frullania disappear in dry lowlands or cool, exposed alpine areas, we would predict that the diversity would diminish. If this is true, we might expect to find the relationship of altitude to diversity to be influenced by the altitude niche width of individual taxa. The collections of $\mathrm{H}$. Inoue on Mt. Albert Edward permit us to examine these relationships.

\section{Collecting Area}

All specimens were collected on Mt. Albert 
Edward, Papua New Guinea, by H. Inoue and identified by S. Hattori(Hattori 1988). The collecting areas extend from $40 \mathrm{~m}$ to $3700 \mathrm{~m}$ altitude (no collections at 500$1000 \mathrm{~m}$ ). Most of the area above 2900$3000 \mathrm{~m}$ is alpine. Below that altitude most, perhaps all, the Frullania grow on trees, whereas in the alpine areas taxa may be found on rocks and shrubs.

\section{Data Analysis}

Taxa diversity, taxa richness (species and infraspecific taxa), and niche width and overlap were calculated using the program COMMANAL, written by the senior author and available through the International Association of Bryology Software Library. Statistical analyses (Student t test, 95\% confidence intervals, Mann-Whitney U test) were done with the microcomputer version of MINITAB.

All 57 taxa were used for the diversity, redundancy, and richness analyses. For the remaining analyses, we used only the 35 taxa with a frequency of $2 \%$ or greater.

Total taxa diversity and diversity by altitudinal zone were computed by both the Shannon-Weaver diversity (Shannon $\&$ Weaver 1949) and the Stirling approximation of the Brillouin information theory-based diversity (Patten 1962; see Glime et al. 1981), using only presence values. These diversities were nearly identical and only the information theorybased results are presented here. Because the values are presence values, there is little meaning to any statistical comparison of diversity by sample among altitudinal zones. However total diversity based on the summation of these samples in each zone is informative.

Species associations were computed using Sorensen's K (1948) and the program COMMANAL.

$$
\mathrm{K}=2 \mathrm{C} /(\mathrm{A}+\mathrm{B})
$$

where $\mathrm{C}=$ the number of co-occurrences of two species

$\mathrm{A}=$ the number of occurrences of species A

$\mathrm{B}=$ the number of occurrences of species B

Niche width and overlap were computed by both the Levins formula (Levins 1968) and the Freeman-Tukey formula (Smith 1982). Unlike the Freeman-Tukey formula, the Levins formula does not account for the rarity of the resource itself. This causes the Levins values to be smaller, and these predict the likelihood of encountering a taxon in a given area. The Freeman-Tukey value is related to the likelihood of encountering the taxon in a niche with any given resource state.

In this study, we partitioned the altitude resource into 10 resource states (with only 7 represented) with $500 \mathrm{~m}$ intervals. We used presence values, since cover values were not available. Glime et al. (1987), using bryophyte communities along mountain streams, showed that when there are sufficient samples, niche width values using presence are comparable to those of cover. The Frullania study was comprised of 648 samples, and this number far exceeds those in the 1987 study.

\section{Results}

\section{Taxa diversity}

Inoue found 57 taxa (Hattori 1988). Taxa diversity (all 57 taxa), redundancy, and taxa richness are presented in Figure 1. As would be expected (Glime et al. 1981), the Brillouin diversities were all lower than the Shannon diversities, but were nearly identical. The alpine zone $(3000 \mathrm{~m}$ and above) has the least diversity, greatest redundancy, and smallest number of species. Likewise, few taxa are represented at low altitudes, with only two being collected below $500 \mathrm{~m}$. Redundancy is considerably higher (redundancy $=1$ ) in 

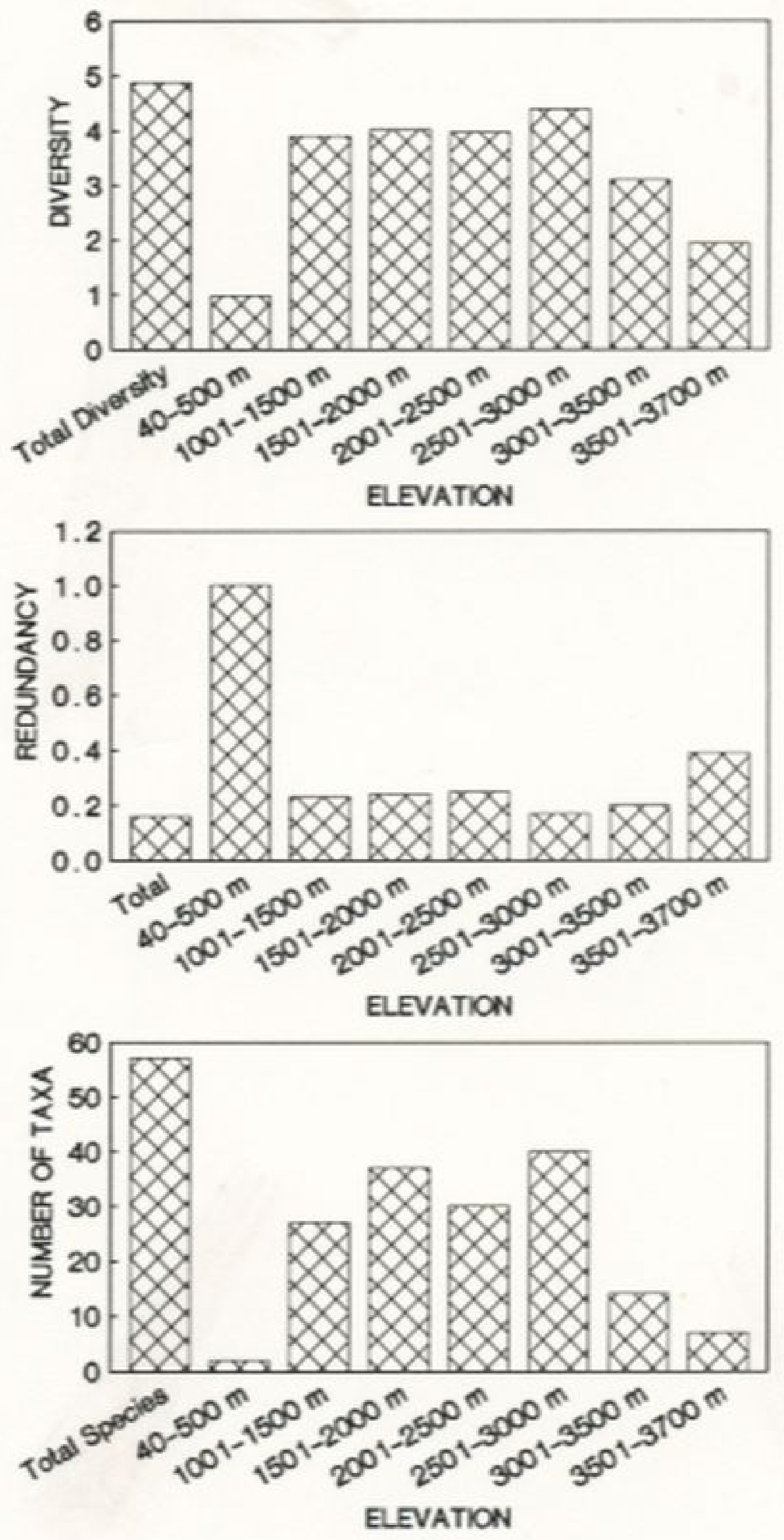

Figure 1. Taxa diversity, redundancy, and number of taxa of Frullania (Mt. Albert Edward, Papua New Guinea) in each resource state using altitude as a niche resource. The altitude resource is partitioned into eight states with 500-meter intervals (state 2 has no collection data). 


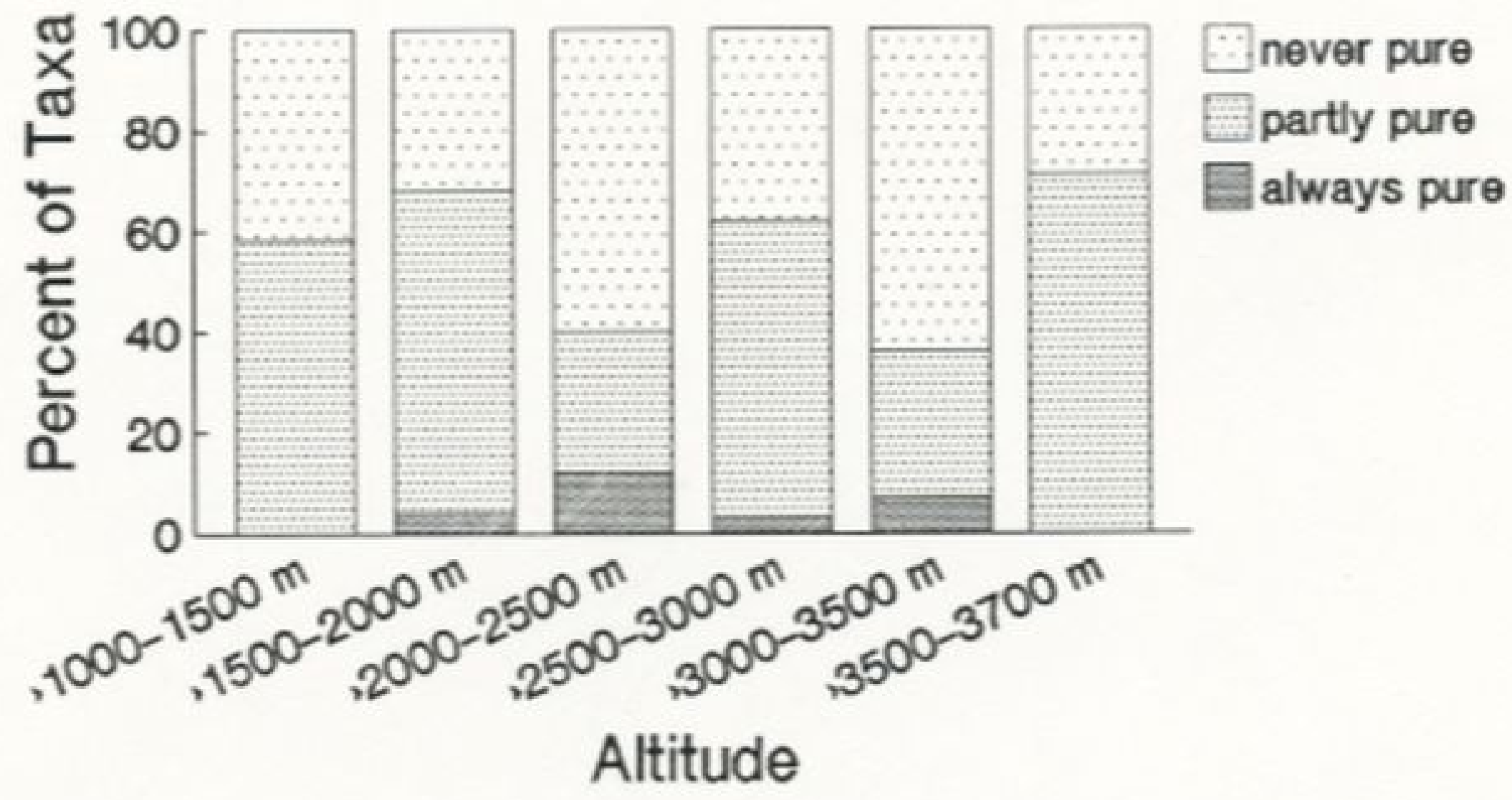

Figure 2. Percentage of taxa (based on 35 taxa with at least $2 \%$ frequency) associated with other taxa at each 500-m altitude interval.

of the taxa ever occur all the time in pure collections with no associated taxa at any altitude, and only four ( $F$. armatifolia, $F$. armitiana var. inflexula, $F$. falsisinuata, and $F$. papillata) occur associated with other taxa in every collection at all altitudes. Instead, most of the taxa occur both as mixed and pure collections, i.e. partly pure.

Table 1 lists the Sorensen's K (1948) value ( $x$ 100 ) of association for the 35 taxa with a frequency of at least $2 \%$. The largest association values are between $F$. serrata var. hamatispina and F. curvistipula var. latistipula (52); F. serrata subsp. spinistipula and $F$. attenuata (40); $F$. serrata var. hamatispina and $F$. grolleana (33); $F$. ornithocephala var. intermedia and $F$. junghuhniana var. tenella (31); F. papuana and $F$. junghuhniana var. tenella (30). All other associations have a $\mathrm{K}$ value of less than 30 .

At each altitudinal level, however, association values may be higher (tables not shown). At $1000-1500 \mathrm{~m}, F$. grandilobula shares a $\mathrm{K}$ value of 50 with both $F$. armitiana var. inflexula and $F$. attenuata. At $1501-2000 \mathrm{~m}$, none of the 28 taxa has a $K$ value greater than 50 with any other taxon. At $2001-2500 \mathrm{~m}$, many associations have $\mathrm{K}$ values above 50 : $F$. armatifolia and
F. falsisinuata (86), F. omithocephala (50), $F$. subdentata (86); $F$.attenuata with $F$. grolleana (54), F. macgregorii (61), F. schusteriana (67), and $F$. serrata subsp. spinistipula (55); F. falsisinuata and $F$. subdentata (100, 3 collections); $F$. grolleana and F. macgregorii (57), F. omithocephala var. intermedia (50), $F$. serrata subsp. spinistipula (50); F. macgregorii and $F$. schusteriana (55), F. serrata subsp.spinistipula (58); $F$. serrata subsp. spinistipula and $F$. omithocephala var. intermedia (52), F. schusteriana (64). At $2501-3000 \mathrm{~m}$, only the association of $F$. curvistipula var. latistipula and $F$. serrata var. hamatispina has a $\mathrm{K}$ value greater than 50 (59). At $3001-3500 \mathrm{~m}$, only two associations have a $\mathrm{K}$ value greater than 50: $F$. falsisinuata and $F$. errans var. angulistipula (60), $F$. junghuhniana var.tenella (64). In the region above $3500 \mathrm{~m}, F$. junghuhniana var.tenella and $F$. omithocephala var. intermedia have a $\mathrm{K}$ value of 57 . Frullania papuana and $F$. omithocephala dominate the collections in this alpine region and have a $\mathrm{K}$ value of 46 .

\section{Niche width}

Niche widths and associated mean altitudes for the 35 taxa with a frequency of $2 \%$ or greater are presented in Figure 3. Frequencies of the 


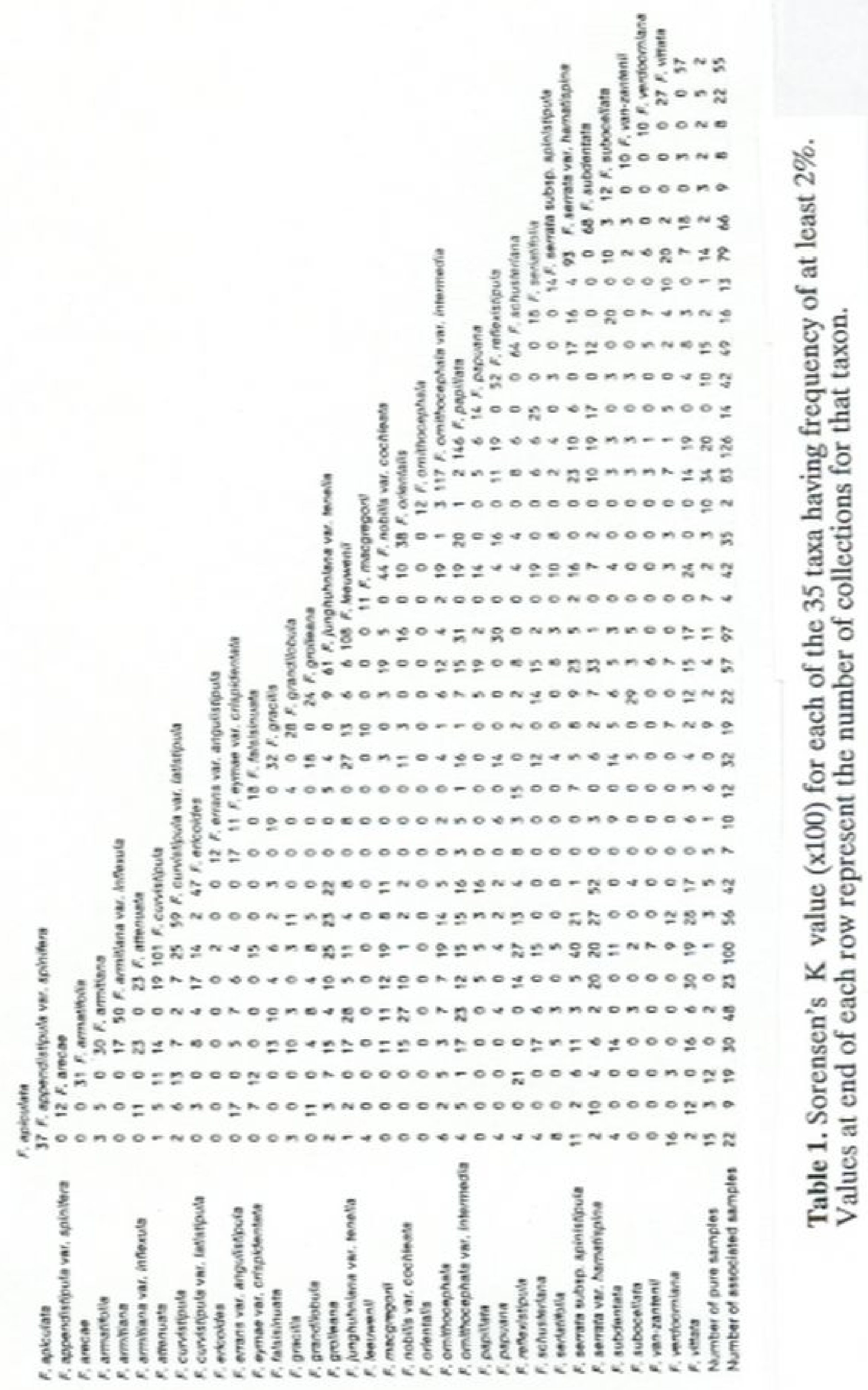


spinistipula and $F$. ornithocephala var. intermedia (52), F. schusteriana (64). At 2501-3000 m, only the association of $F$. curvistipula var. latistipula and $F$. serrata var. hamatispina has a $\mathrm{K}$ value greater than 50 (59). At 3001-3500 m, only two associations have a $\mathrm{K}$ value greater than 50: $F$. falsisinuata and $F$. errans var. angulistipula (60), F. junghuhniana var. tenella (64). In the region above $3500 \mathrm{~m}$, $F$. junghuhniana var. tenella and $F$. ornithocephala var. intermedia have a $\mathrm{K}$ value of 57. Frullania papuana and $F$. ornithocephala dominate the collections in this alpine region and have a $\mathrm{K}$ value of 46.

\section{Niche width}

Niche widths and associated mean altitudes for the 35 taxa with a frequency of $2 \%$ or greater are presented in Figure 3. Frequencies of the 35 taxa in each altitudinal resource state are presented in Figure 4.

The broadest niches are those of $F$. apiculata, F. appendistipula var. spinifera, $F$. armatifolia, $F$. attenuata, $F$. errans var. angulistipula, $F$. gracilis, $F$. ornithocephala, and $F$. ornithocephala var. intermedia.

As predicted, the Freeman-Tukey niche width values are all larger (mean 0.80 $\pm 0.04)$ than those of the Levins formula (mean $0.35 \pm 0.04$ ).

Mean altitudes for the taxa ranged from $1622 \mathrm{~m}$ to $3147 \mathrm{~m}$, with only two taxa $(F$. papuana and $F$. armitiana) having a mean altitude above $3000 \mathrm{~m}$. Even so, $F$. papuana was collected once below 1500 $\mathrm{m}$.

\section{Niche overlap}

Freeman-Tukey niche overlap values for the 35 taxa with a frequency of $2 \%$ or greater are presented in Figure 5. The mean F-T overlap was $0.65 \pm 0.02$ for 595 pairs of taxa; the mean Levins overlap was $0.52 \pm 0.026$. Many altitudinal distributions (28\%) for the taxa pairs were significantly different $(=0.01$, non-parametric MannWhitney U test). Using only three states (40-1500 m, 1501-3000 m, and >3000) instead of 500-m intervals resulted in broader overlaps; the three-state results are not presented here.

\section{Sibling taxa}

Niche width and altitudinal range for the four pairs of sibling taxa with a frequency of $2 \%$ or greater and frequency values in each of the resource states for altitude for each of these taxa are presented in Figure 6.

In Figure 6, one can easily see that the ranges of the infraspecific taxa differ substantially between siblings. Frullania armitiana $($ mean altitude $=3101 \mathrm{~m}, \mathrm{~F}-\mathrm{T}$ width $=0.70)$ is significantly separated $(=$ 0.05, Mann-Whitney Utest) from its variety $F$. armitiana var. inflexula (mean altitude $=2600 \mathrm{~m}, \mathrm{~F}-\mathrm{T}$ width $=0.80$ ), with an FT overlap of 0.61 . F. curvistipula (mean altitude $=2120 \mathrm{~m}, \mathrm{~F}-\mathrm{T}$ width $=0.93)$ is significantly separated from $F$. curvistipula var. latistipula (mean altitude $=2717 \mathrm{~m}$, F-T width $=0.67)$, with an F-T overlap of 0.67 . F. ornithocephala (mean altitude $=$ $2331 \mathrm{~m}, \mathrm{~F}-\mathrm{T}$ width $=0.99$ ) is significantly separated from its variety, $F$. ornithocephala var. intermedia (mean altitude $=2730 \mathrm{~m}, \mathrm{~F}-\mathrm{T}$ width $=0.95)$, with an F-T overlap of 0.92. F. serrata subsp. spinistipula (mean altitude $=1845 \mathrm{~m}, \mathrm{~F}-\mathrm{T}$ width $=0.79)$ is significantly separated from $F$. serrata var. hamatispina (mean altitude $=2474 \mathrm{~m}, \mathrm{~F}-\mathrm{T}$ width $=0.76$ ) with an F-T overlap of 0.66 .

\section{Discussion}

\section{Associations}

The middle altitudes support more taxa and higher diversity than either the lowland 


\begin{tabular}{llll}
\hline LEVNS & F-T & ALTITUDE \\
& & & \\
& & \\
\hline
\end{tabular}

Dendrogram Group 2

Frullania eymae var. crispidentata Frullania orientalis

Frullania arecae

Fruillania verdoorniana

Frullania ericoides*

Frullenia van-zantenï

Frullania reflexistipula

Frullania serrata subsp. spinistipula

Frullania leeuwenil

Frullania epiculata

Frullania attenuata

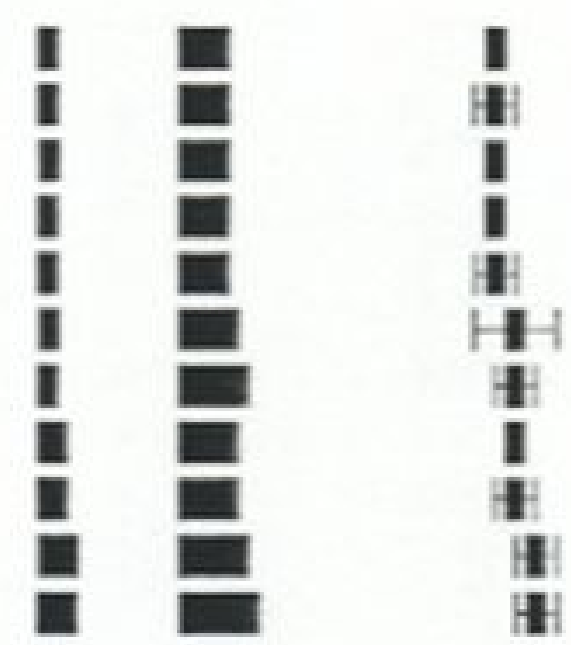

Transition Group

Frullania gracilis

Frullania appendistipula var. spinilera

Frullania curvistipula

Frullania grolleana

Frullania schusteriana

Frullania seriatifolia

Frullania ornithocephala

Frullania papillata

Frullania serrata var, hamatispina

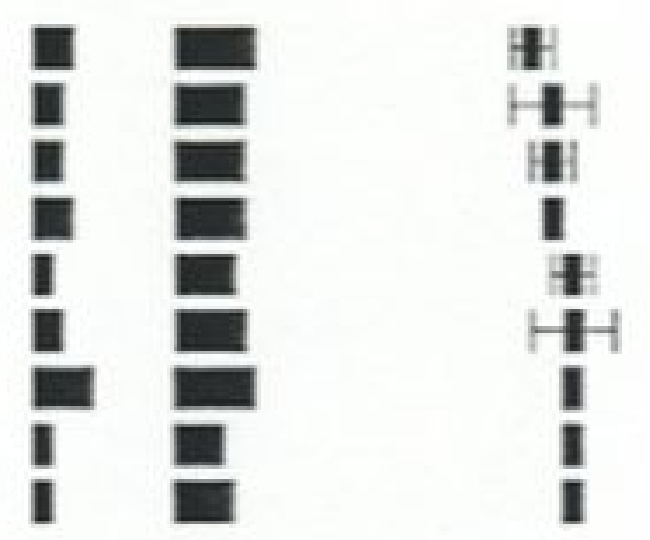

Dendrogram Group 1

Frullania subocellata

Frullania subdentata

Frullania errans var. engulistipula

Frullania armitiana var, infiexula*

Frullania vittata

Frullania grandilobula

Frullania armatifolia

Frullania curvistipula var. latistipula*

Frullania ornithocephala var. intermedia

Frullania macgregorii

Fruillania junghuhniana var, tenella

Frullania falsisinuata

Frullanie nobilis var. cochleata

Frullania armitiana

Frullania pepuana

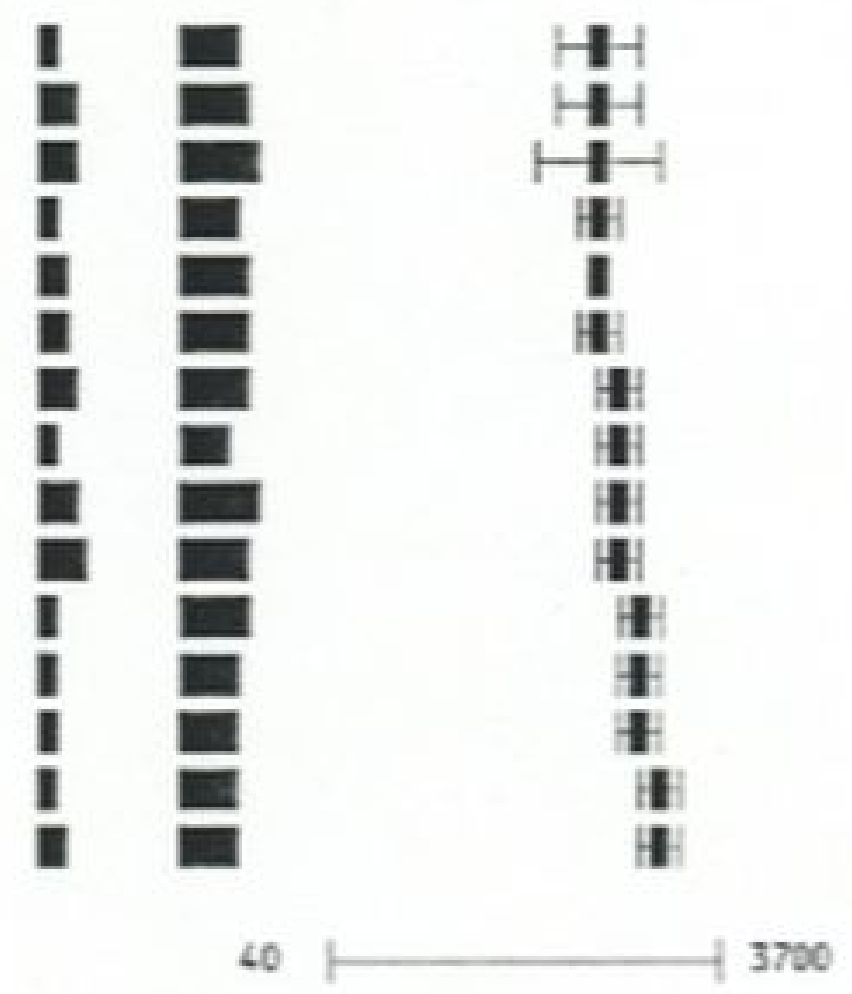

Figure 3. Levins and Freeman-Tukey niche width values for 35 Frullania taxa (Mt. Albert Edward, Papua New Guinea) for the resource altitude. Dendrogram groups refer to those of $\mathrm{Li}$ et al. (1989) and generally correspond to low (group 2) and high (group 1) altitude groups. *Indicates taxon that belongs to the opposite group from the one where it appears in this figure. Altitude indicates mean altitude of occurrence with $95 \%$ confidence interval indicated by brackets. Mean Levins niche width $=0.35 \pm 0.041$. Mean Freeman-Tukey niche width $=0.80 \pm 0.038$. (Number samples $=648$; range of altitude $=40$ to $3700 \mathrm{~m}$; altitude is divided into 10 states [with 3 having no collections] with $500 \mathrm{~m}$ intervals; only taxa with frequency of $2 \%$ or more are included.) 
or alpine region (Fig. 1). Likewise, only at the middle altitudes are there taxa that always occur in pure collections (Fig. 2). On the other hand, at 2000-2500 m, we find the highest number of associations with a $\mathrm{K}$ value greater than 50 , suggesting that at this altitudinal range some benefit might be derived from an association. This K value implies that the taxa are not only associated with other taxa, but that there is a high degree of fidelity in the association.

Several advantages can be gained by an association formed among epiphytic liverworts.

1. Small liverworts can live among larger ones and be protected from high light intensity in the forest canopy or in exposed alpine areas.

2. Associated liverworts can protect each other from drying out by reducing the amount of free space among the branches and leaves.

3. Liverworts that have a poor ability to move water from the substrate or surface of the clump to their own branches can take advantage of the water moved by an associated species.

Although few authors describe such commensal relationships in plants, Rydin (1985) has suggested that they exist among Sphagnum species with differential abilities to absorb water in one circumstance and to retain it in another. His conclusions are further supported by the studies of $\mathrm{Li}$ (unpublished data) on two additional species of Sphagnum.

One must, however, exercise caution in interpreting such circumstantial evidence, for it might merely be ephemeral coexistence manifest at this single point in time. The evidence torefute this statement, however, is the preponderance of taxa that never occur in pure collections (Fig. 2). We must interpret this to mean that the associated taxa are always struggling in a habitat where no suitable free space exists or that there is in fact some benefit in coexistence.

\section{Niche trends}

The distribution of niche widths appears to be related to diversity and sample purity. Taxa at the low and high ends of the altitudinal range tend to have narrower niches than those taxa in the middle. Certainly part of this narrowness results from fewer collections in the low and high altitudes. On the other hand, the smaller number of collections is in turn a result of the reduced availability of Frullania to be collected at these altitudes.

The Levins niche widths and FreemanTukey niche widths are considerably different, indicating that the niche states (i.e. altitudes) were not equally available among the collections. Because it is sensitive to the availability of the niche, the Levins width tells us how common the taxa might be, compared with other taxa, if we examined the area without regard to altitude. The Freeman-Tukey width, on the other hand, tells us the potential for each taxon if its niche (resource state) were equally available to that of all other resource states. For example, the smallest niche width is that of $F$. papillata $(\mathrm{F}-\mathrm{T}=$ 0.57 ), with $95 \%$ of its observations expected between 2368 and $2575 \mathrm{~m}$. In fact, we find that it occurs in only two altitude ranges, between 2500 and 3500 $\mathrm{m}$.

We can conclude that most of these Frullania taxa could occupy niches in most of the altitudinal ranges, but because of other factors, they are most successful in a relatively narrow range. Several observations support this statement.

When one examines the mean altitudes and $95 \%$ confidence intervals for each taxon of Frullania (Fig. 3), it is clear that many taxa have rather narrow altitudinal 


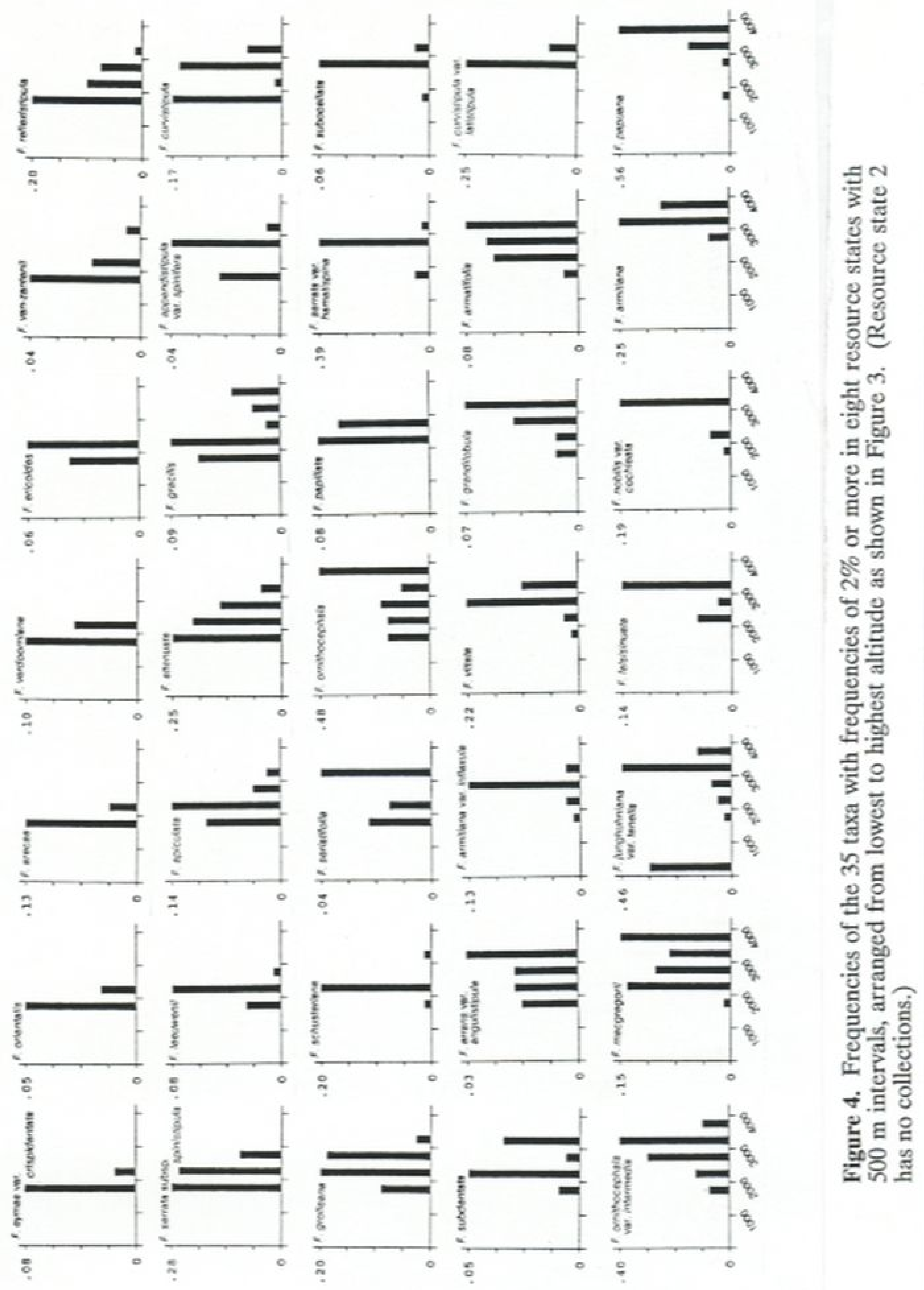



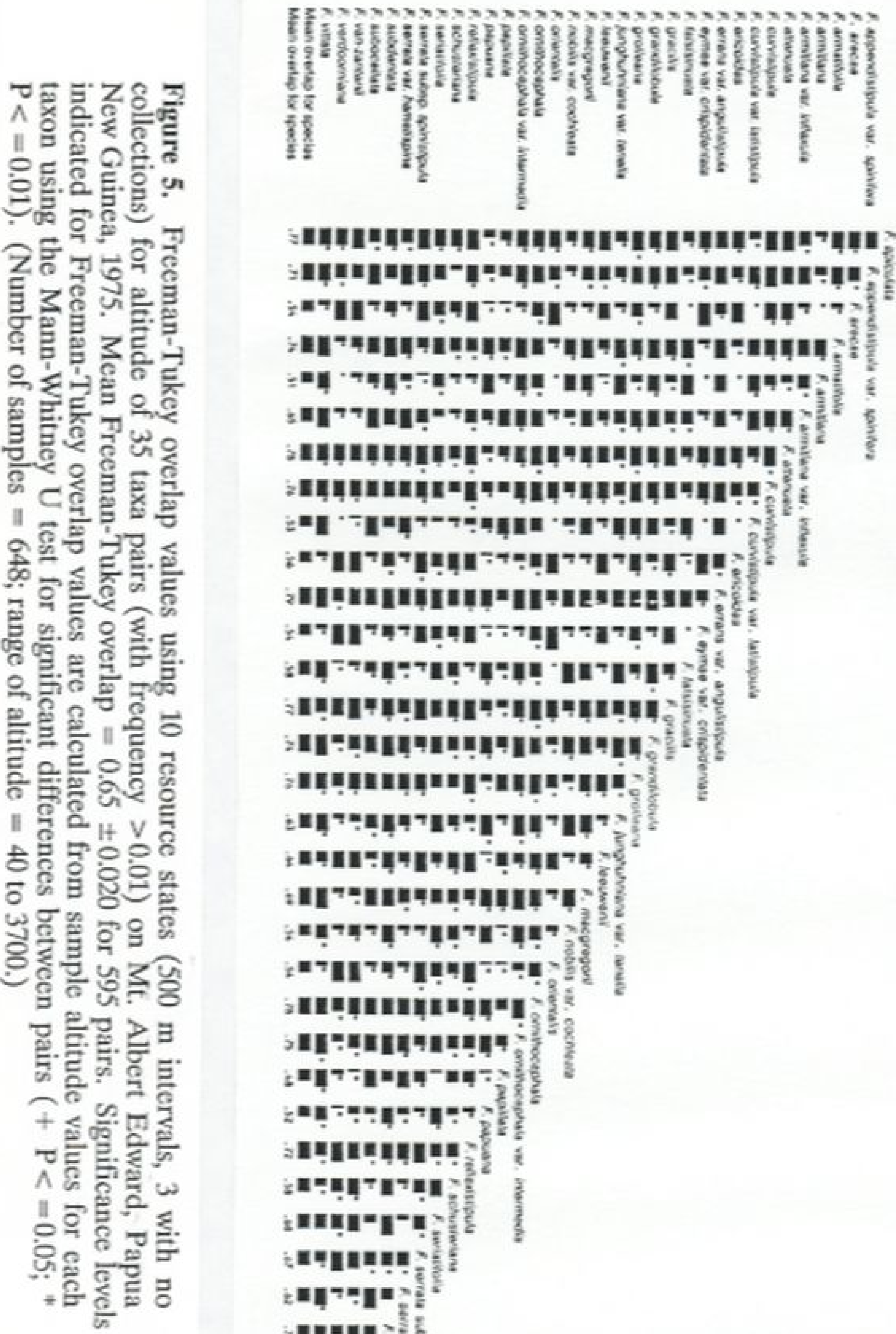

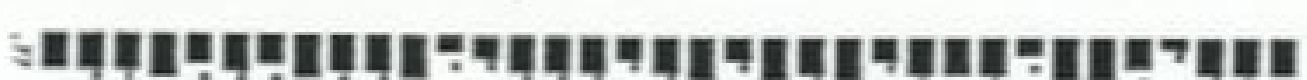

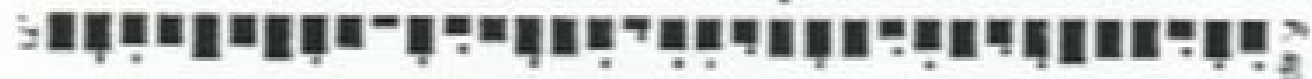

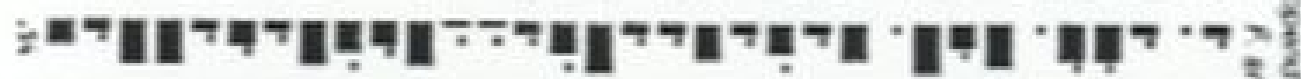

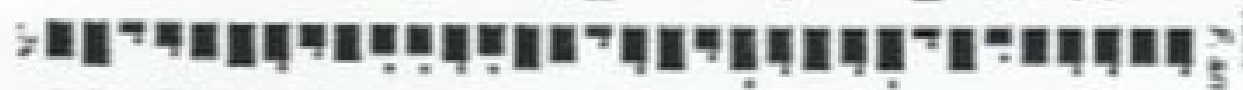

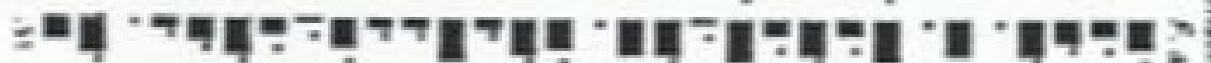
\$

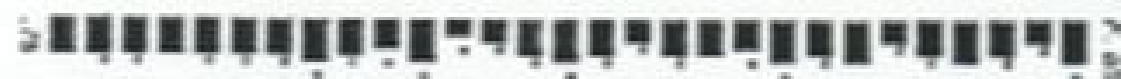

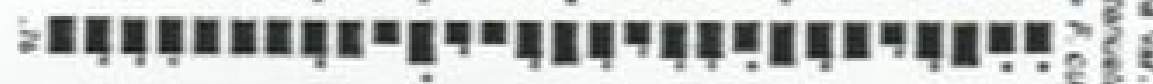

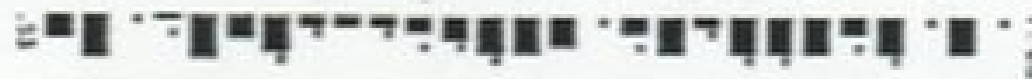

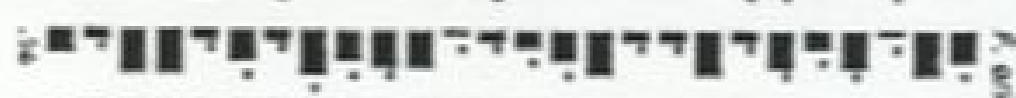

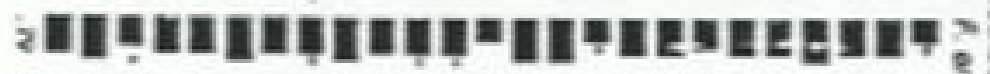
;

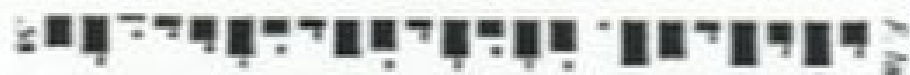

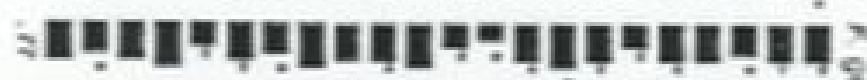

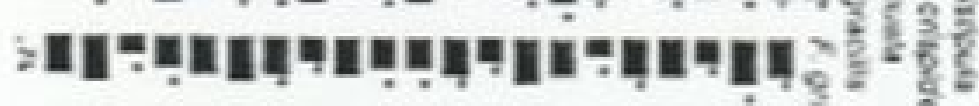
;

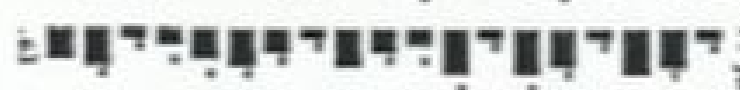

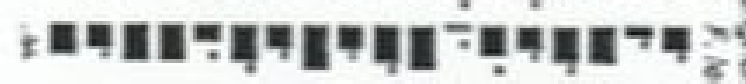

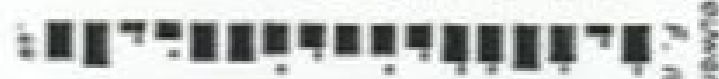
;

i

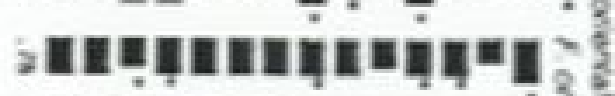

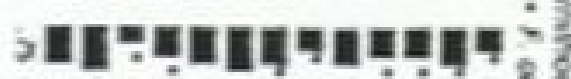

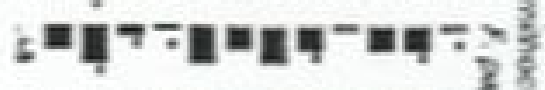

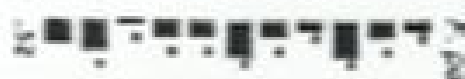

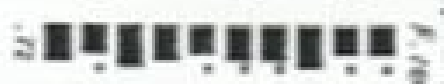

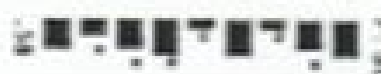

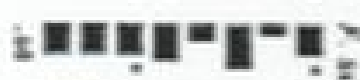

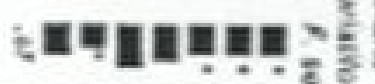

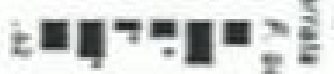

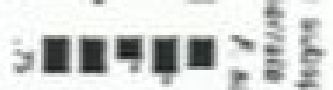
ind i $m=1$ का 
preferences, as shown by their narrow 95\% confidence ranges (Fig. 3). Such taxa include $F$. apiculata, $F$. attenuata, $F$. gracilis, $F$. ornithocephala, and $F$. ornithocephala_var.intermedia.

Among the 35 Frullania taxa, $28 \%$ of the taxa pairs (Fig. 5) have members that have significantly different altitudes of collection $\left({ }^{\circ}=0.01\right.$, Mann-Whitney U test), suggesting that the overlap difference is significant. These include taxa that occur in a wide range of altitudes (Fig. 4) and have broad niche widths.

By contrast, F. errans_var. angulistipula has the widest $95 \%$ confidence range about its mean altitude, and a wide niche width (0.96), with no significantly different altitudinal values when compared with any other species at " $=0.01$.

Li et al. (1989) suggested that these taxa separate into two major groups (dendrogram based on TWINSPAN analysis of these data) corresponding to lower and higher altitudes. Likewise, the Li PCA axis three separates the high altitude taxa at one end and the low altitude taxa at the other end. In Figure 3, we have listed the taxa of the dendrogram groups, showing that when the taxa are ordered by their mean altitudes their arrangement corresponds closely with the dendrogram separation. It is noteworthy that those taxa that were not faithful to the appropriate altitudinal branch are those taxa preferring middle altitudes, and we have labelled these the Transition Group. The far ends of Groups 1 and 2 are taxa with relatively narrow niche widths.

\section{Sibling taxa}

Landolt (1977) stressed the importance of closely related taxa for the delimitation of phytosociological units. He showed that the sub-classifications of a species can be of particular importance for separating plant associations that contain few species.
Horton (1988) used niche width measurements for soil $\mathrm{pH}$, calcium, and magnesium to support her separation of several questionable taxa of Encalypta. Shaw (1981) showed that the morphological variation of two species of Pohlia correlated with niche variation, and he concluded that combining taxa based on overlapping form alone can result in the loss of ecological information (Shaw 1985). Landolt (1977) concluded that in places where crucial ecological factors undergo a sudden change, even closely related taxa, not isolated genetically, mutually exclude one another to a large degree. Closely related taxa can thus be considered as very good character- or differential species for describing associations. The present study contains several species that have more than one variety or subspecies present, and provides an interesting comparison of niches for these controversial taxa.

To use niche width as either a taxonomic separator or as an association separator, the data must meet several important criteria:

1. The infraspecific taxa must be consistently identifiable by the person naming the taxa.

2. The niche parameter must have a sufficiently wide range among the samples to provide for a niche separation.

3. There must be sufficient samples throughout that wide range to permit adequate comparison.

4. The parameter for delimiting the niche must differ significantly between the taxa being compared.

Landolt (1977) listed three problems in using infraspecific taxa in phytosociological studies:

1. Few polymorphous species groups have been sufficiently investigated biosystematically to assure conclusive evidence on the value of the taxa involved, 


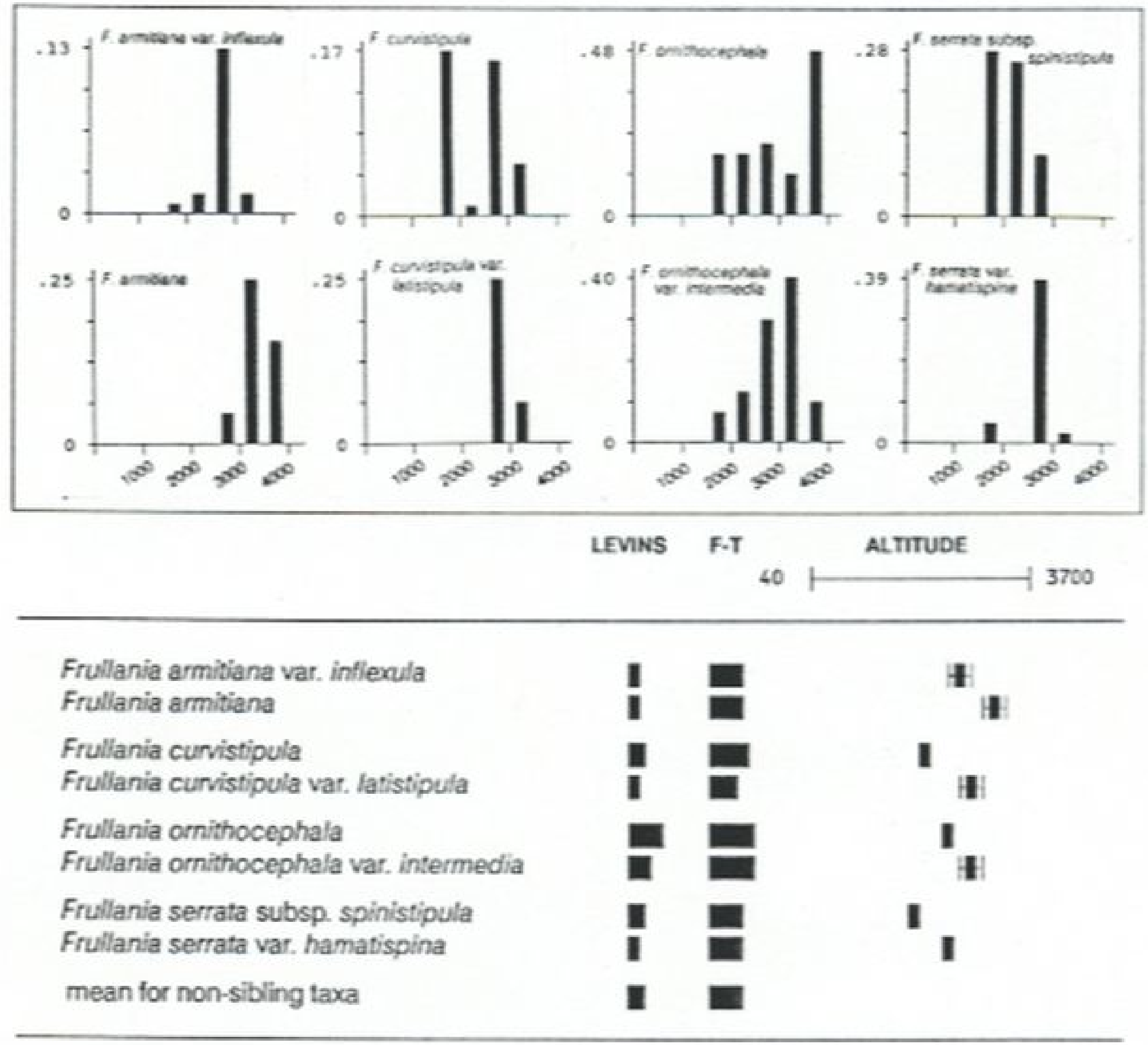

Figure 6. Relationships of four pairs of sibling taxa. Top: Frequencies of taxa in eight altitudinal resource states with $500 \mathrm{~m}$ intervals. (No collections were made at $500-1000 \mathrm{~m}$.) Bottom: Niche width, mean altitudes, and $95 \%$ confidence intervals, illustrating the difference in niches of the two members of sibling pairs. 
so that we do not know if the described types are really genetically fixed.

2. It is almost impossible for a phytosociologist to identify these taxa.

3. Taxa occurring within a given group often have a very limited distribution and thus are not identical to similar taxa in other areas.

These problems are essentially eliminated in the present study. Hattori has made a lifelong study of the genus and has identified all the specimens included in the study. Even if they are not true genetic taxa, the naming of the morphotype (whether it be genetic or ecological) provides evidence that can describe an association. All taxa were collected and identified in the laboratory where it was possible to compare specimens and be consistent in naming. The geographic area of concern in this study is a single mountain, so any distributional limitation is irrelevant.

Some interesting differences in altitudinal distribution are present among the sibling taxa of Frullania (Fig. 6). The altitudes of collection of the members of all the sibling pairs are significantly different from each other, in spite of rather broad niches, yet only $28 \%$ of the 35 taxa analyzed have significantly different altitudes of collection. The very broad niche widths of $F$. ornithocephala and its variety $F$. ornithocephala var. intermedia illustrate that even closely related taxa with very wide niches can have different optimal niches. This is best shown in Figure 6, where it is clear that $F$. ornithocephala is dominant in the alpine regions, whereas $F$. ornithocephala var. intermedia is dominate below. Likewise, $F$. armitiana is dominant at higher altitudes, whereas $F$. armitiana var. inflexula becomes dominant just below, where $F$. armitiana begins to drop out. A similar shift occurs in the infraspecific taxa of $F$. serrata. Such shifts in abundance suggest that other niche parameters serve to separate the members of these infraspecific taxa pairs when they occur at the same altitudes.

Frullania curvistipula has a bimodal distribution that broadly overlaps $F$. curvistipula var. latistipula between 2500 and $3000 \mathrm{~m}$. The variety, on the other hand, is restricted to the upper end of the $F$. curvistipularange. Some environmental factor depresses the population of $F$. curvistipula in the $2000-2500 \mathrm{~m}$ range, where $F$. attenuata, $F$. macgregorii, $F$. serrata subsp. spinistipula, and $F$. schusteriana are dominant. Among these 'competing' taxa, all have broad ranges that overlap the peaks of the $F$. curvistipula range, except for $F$. schusteriana. We can conclude that $F$. schusteriana has probably not competitively replaced $F$. curvistipula in the middle of the $F$. curvistipula range because the former is a slender, pendent species, whereas the latter is a medium-sized, mat-forming species. On the other hand, the presence of pendent forms such as $F$. schusteriana and $F$. papillata suggests that it may have been more moist in the $2000-2500$ m range. It is therefore interesting that the variety $F$. curvistipula var. latistipula is likewise absent in this range, suggesting that it has similar physiological characters that prevent it from occupying this range.

In the present study, we have shown that the members of sibling pairs have different optima for altitude on Mt. Albert Edward and that they rarely were identified together. From these observations, we can conclude one of the following:

1. Investigator bias in identification has resulted in the implied distribution pattern. 2 . The siblings are genetically distinct and mostly allopatric.

or

3. The siblings are ecological variants induced by altitudinally related factors.

Common garden or transplant tests are 
Sorensen's $K \times 100$

F. armitiana x
F. armitiana var. inflexula
$\begin{aligned} & \text { F. curvistipula x } \\ & \text { F. curvistipula var. latistipula }\end{aligned}$
$\begin{aligned} & \text { F. ornithocephala x } \\ & \text { F. ornithocephala var. intermedia }\end{aligned}$
$\begin{aligned} & \text { F. serrata subsp. spinistipula x } \\ & \text { F. serrata var. hamatispina }\end{aligned}$

Table 2. Sorensen's K value for sibling pairs.

ferences while having relatively broad overlaps.

\section{Literature Cited}

Glime, J. M., Trynoski, S. E., \& Short, F. T. (1981) Bryophyte diversity: case studies using the Brillouin index to describe epiphytes and an alkaline marsh. Journal of the Hattori Botanical Laboratory 50: 179-190.

Glime, J. M., Slack, N. G., \& Meston, C. E. (1987) A comparison of the Levins' and Freeman-Tukey niche width measures for the bryophytes in an Adirondack stream. Symposia Biologica Hungarica 35: 457-466.

Hattori, S. (1988) Frullania flora of Mt. Albert Edward, Papua New Guinca. Journal of the Hattori Botanical Laboratory 65: 411-453.

\& Piippo, S. (1986) Bryophyte flora of the Huon

Peninsula, Papua New Guinea. XV. Frullania (Prullaniaceae, Hepaticae). Acta Botanica Fennica 133: 25-58.

Horton, D. G. (1988) Microhabitats of the New World Encalyptaceac (Bryopsida): Distribution along edaphic gradients. Beiheft Nova Hedwigia 90: 261-282.

Landolt, E. (1977) The importance of closely related taxa for the delimitation of phytosociological units. Vegetatio
34: $179-189$

Li, X., Glime, J. M., \& Hattori, S. (1989) Ecological gradient analysis of the genus Frullania on Mt. Albert Edward, Papua New Guinea. Journal of the Hattori Botanical Laboratory 66: 359-369.

McNaughton, S. J. (1966) Ecotype function in the Typha community type. Ecological Monographs 36: 297-325.

Patten, B.C (1962) Species diversity in net phytoplankton of Raritan Bay. Journal of Marine Research 20(1): 57-75. Rydin, H. (1985) Effect of water level on desiccation of Sphagnum in relation to surrounding Sphagna. Oikos 45 : 374-379.

Shannon, C. E, \& Weaver, W. (1949) The mathematical theory of communication. University of Illinois Press, Chicago.

Shaw, A. J. (1981) Ecological diversification among nine species of Pohlia (Musci) in western North America. Canadian Journal of Botany 62: 219.229.

Shaw, J. (1985) The relevance of ecology to species concepts in bryophytes. The Bryologist 88: 100-206.

Smith, E. P. (1982) Niche breadth, resource availability, and inference. Ecology 63: 1675-1681.

Sorensen, T. (1948) A method of establishing groups of equal amplitude in plant sociology based on similarity of species content and its application on Danish commons. K. Danske Vidensk. Selsk, Biol. Skr. 5: 1-34. 